\title{
The Importance of Infrastructures in the LDC's Economic Sustainable Development
}

\author{
Romeo Ciminello ${ }^{1}$
}

\begin{abstract}
Infrastructures are crucial for sustainable growth and inclusive development of Less Developed Countries. The problem in hypothesis is the African infrastructure gap, that neither governments nor civil society organizations seems to want to face promoting investments in tangible programs that take into consideration such kinds of important elements aimed to an equal durable and sustainable improvement. The paper starts with a description of recent initiatives to scale up infrastructure investment in Africa. The methodology follows a scheme of hypothesis, observations experiences and data collection from $\mathrm{ADB}$ and others Institutions. This research tries to let understand what is the connection between development and infrastructures for human being. The paper then uses insights from the literature on informed versus arm's length debt to discuss the structure of infrastructure financing. The economic growth and its goal, outlines the difference between structures and infrastructures. The main effort is how to give a weight to these latter in order to measure the empowerment of people that pass through their standard of living based on a system of strategic priorities centered on infrastructure package investments. Understanding the importance of infrastructures helps to satisfy needs and implement services that even if deemed not essential and substantial, are anyway most important to the growth of personal and social conditions. In this context the analysis is made on the difference between economic growth and development grounded on structure and infrastructure. The effort is to try to identify indicators able to evidence the contribution ratio of infrastructures to the development, how this can be measured and how they work in the different fields. The conclusion and implications are that to yield such potential global benefits, Africa's industrialization would have to be underpinned by a robust infrastructure financing program. This requires a global finance pact among advanced and developing countries, a shift in strategic approaches, and new models of financing.
\end{abstract}

Keywords: Africa, Infrastructure Finance, Economic growth, Development Banks, Integral development economy, Long-term Investors, Development indicators, Economy of Francesco, Lonergan's new economic vision

\section{Introduction}

Infrastructure for sustainable and inclusive development is a topic of research that is poorly discussed in the international forum. We think instead that the infrastructures have great potential in sustainable development even if they are not yet considered as a crucial and strategic element that could have a very big impact on inclusive growth and on the promotion of the common good.

The work focuses on how to conceive the link between development and infrastructure for the human being. The distinction between the meaning of development and that of economic growth also clarifies the difference between structures and infrastructures, to obtain human results with infrastructure investments in Africa.

It is very important to apply a criterion on the social and moral impact of authentic development and judgment on the role of infrastructures and their financing purpose. The points presented are: the methodology, the meaning of the concept of development

\footnotetext{
${ }^{1}$ Director of Hermes University in Rome (www.unihermes.org). Teaches Ethics and Development in the Faculty of Economics and Development of the Catholic University of Congo DRC - Kinshasa.
} 
and its difference with the concept of economic growth and its objectives. The development triangle. Finally the distinction between structure and notion of infrastructure. It is also essential to identify how the weight of infrastructures could be calculated in their contribution to development.

To capture the potential global benefits, a new vision and a new infrastructure financing model is needed thanks to their support for the common good.

\subsection{Methodology}

The methodology respects the canons of the scientific method and in which all the single steps and the individual choices are expressed in a clear and precise way and, therefore, possibly criticizable. It is not easy to show something completely new in this context where the meaning of the infrastructure refers only to energy, water, sanitation, ICT (telephony) and transport and the way they are currently financed. This is why we use B.J. Lonergan's Methodology as a foundational path of knowledge based on three conversions: intellectual conversion, which requires attention to the experience and events that come to us naturally and to intelligence, to order them intelligibly for their use; moral conversion, aimed at the reasonable and responsible evaluation of the facts observed in the intellectual phase to express rational judgments, based on a solid perception of the consequences deriving from this evaluation; religious conversion, which leads to the awareness of the historical condition of the human being and to his need to take into account the fact that his actions are always connected in a double way: in the immanent bond to the transcendent and in the present linked to the future, so that every action always has an impact on our human nature and on future generations.

\section{Meaning of Development and Difference with the Economic Growth}

Often and erroneously economists, especially those of the last century, have confused the two concepts in a not very analytical way. In fact the difference between them is evident if a punctual scientific analysis is carried out. We try to clarify the difference between development and economic growth in a timely manner.

\subsection{The integral development of man}

Human development is a much greater challenge than overcoming simple poverty through an increase in wealth. The first distinction is between development and integral development. The lack of integral development should be interpreted as a structural violation of human rights that are an integral part of human development, whose respect is essential for peace, which according to the encyclical Populorum Progressio represents the other name of development. (Paolo VI, 1967).

Development is at the same time a process and a result: a process as a choice to manage everything that concerns natural resources sparingly and increasingly at risk of being exhausted. Contrary to what degrowth economists propose, resources must be consciously used in an efficient manner that respects the aims and objectives of integral human development. The cultural process of economic choices must be based on a new paradigm for which, instead of saving resources, one should use them without destroying them, in the context of a circular and regenerative economy considering the needs of 
future generations. This management is a process of necessary choices because the modern economy does not place limits on consumption and excessive use of resources, nor does it care about the responsibility we have towards those who come after us. Development then is a result because its achievement represents the goal of the common good which consists in the affirmation of the human dignity of each man based on the existential freedom and on the increase of his knowledge and functional abilities and therefore on the increase of his abilities of freely choose how to self-determine.

The concept of integral human development is the central point sanctioned by the Second Vatican Council of the Catholic Church in its Pastoral Constitution Gaudium et Spes. (Vatican Council II 1966). The evaluation of the integral development must foresee for each country the examination of the existing potentialities observed in all the aspects, materials, animals, and humans; it must aim not only at the current problems of the globalization of political freedom, cultural identity and the security of the integrity of the human being, but also and above all how new technologies ${ }^{1}$ will affect the development of future generations.

\subsection{The path to economic growth}

The economic growth considers only the result achieved on the basis of a systematic survey process represented by the G.D.P.. The economic growth accounted for through this indicator does not give true indications of development because it adds both positive and negative factors. Its calculation is based on an annual cycle that contemplates the aggregate of its kind, but which can also be considered "grossly" as an indicator of wealth and individual well-being by simply dividing it by the number of inhabitants of the country: GDP per capita.

\subsection{Objectives of economic growth}

Economic growth is important because it helps to increase the total wealth of a nation and improve the potential for poverty reduction. The improvement of human development certainly depends on the way in which this growth is generated. In fact, if we analyze more deeply we find that it clearly distinguishes itself from the concept of development in that it can be achieved through a series of contradictory objectives such as:

1) economic growth that favors the accumulation of wealth unequally shows an economic growth without solidarity;

2) economic growth that favors the accumulation of capital based on unemployment, this objective shows an economic growth without work;

3) an economic growth that depresses the poorer classes of workers and that gives rise to a class struggle that weakens the democratic fabric of the country, well explained by Jeremy Rifkin in his book "The access era" (Rifkin 2001). This economic growth underlines the objective of silencing the voice of the weakest;

4) an economic growth that depersonalizes the cultural identity of the solidarity traditions existing in a country shows an economic growth without human roots;

5 ) economic growth as a continuous and massive exploitation of existing resources that

1 The new Technologies: info-technology, nano-technology, bio-technology and cogno-technology 
endanger the environment through pollution is an economic growth with no future.

\subsection{How to measure development differently from economic growth?}

After these clarifications I believe that it is no longer necessary to ask the question why there is a need to find new indicators with respect to GDP. The increase in wealth as calculated up to now does not take into account how the value is produced, i.e. whether from a humanly positive transaction (the increase in workers) or negative (sale of arms, earthquakes, etc.) or from technological progress. So as far as development is concerned, in addition to the various existing indices such as:

- the HDI (Human Development Index) as a global measure of the achievements of human development;

- the HPI (Human Poverty Index) as a measure of lack of conditions and determinants of human poverty;

- the GIHD (Gender Indicator of Human Development) as a measure of gender inequality in human development;

- the IFP (Index of Female Participation) as a measure of gender equality in economic and political participation in the venues where the socio-political-economic destiny of the country's structures is decided (Ugaz 2008); it appears necessary to implement the new index proposed by the School of Economics of integral development of the Man of Kinshasa (DRC) the U.P.I. (Unexploited Potential Index) as an overall index of all the aforementioned indices incorporated in the concept of potentialities existing in a country. (European Journal of Sustainable Development 2017)

\section{The Triangle of Development and the Necessary Elements to Reach a Reliable Result}

The development triangle is based on the three fundamental projects: 1) the social planning, which focuses on the type of society that we want to reach over the next fifty years what kind of classes to identify; 2) the political planning as a support to the social one with the aim of a common good properly understood; 3) the economic planning as a support element for the other two projects in terms of capacity utilization of existing assets and available to the community.

So the elements necessary to achieve the goals represented by the vertices of the triangle are found in the design skills linked to the existing potential both at a social level where culture is the fundamental element of development that bases its path towards a progressive increase of civilization given by the evolution of the human being that is felt in the need to achieve four important needs goals:

a) the need to be clean and to live and work in a healthy and clean environment, therefore the need to be able to wash oneself, to look after one's own person, one's appearance, to have clean clothes, to live in a comfortable home, to not to have rubbish near you, to have a bathroom, etc .;

b) the need to use a more polished and complete language, to be able to use terms that are less vulgar or bad-mannered and more responsive to one's own thought, to use a language less linked to dialect terms and more respectful of literal figures that allow a more captivating and dialectical dialogue interactive; 
c) the need to settle disputes in a non-violent manner, respectful of the rules and based on a discussion based on facts from which criteria of judgment can be drawn to determine a convergence of opinions towards the correct definition of a cause;

d) finally, the need to respect the rules and regulations governing coexistence in relationships, at the organizational level in the social context and the awareness of respect for moral rules in the ethical context of existential reality.

That is why we promote adequate infrastructure for the development of the human community.

\section{Difference between Structures and Infrastructures}

The presence of structures in itself also implies the concept of infrastructures, that is to say link connections that allow the use and proper functioning of existing structures in a country.

\subsection{Structures}

The concept of structures immediately involves the image of something rigid, defined, not easily variable. But if this is valid for material reality, the same is true for what concerns the social structure of a state as the configuration of a set of people existing in a territory. We can therefore simplify the discourse by calling structures all that represents an immobilization, above all public, that is to say something that cannot be easily changed within a certain territorial area and for whose change requires a variation difficult to be implemented and which requires of certain techniques, and times. Public fixed assets also include private assets and two unique types of resources: infrastructure assets and assets.

\subsection{Infrastructures}

Infrastructure means the series of structured elements interposed between the various components of a structure. There are institutional or critical infrastructures, which collect various organizations with functions that are also separate from each other, such as the defense or the banking or communications system, which are part of a strategic set in which the sale or loss of a single element risks dragging everything else . In the economic context we define as "infrastructure" the network of goods and services fundamental for the socio-economic development of the country because it facilitates and promotes the relationships between the parties. This network represents the socalled social fixed capital comprising transport, energy and telecommunications as primary services, or that series of infrastructures that must have high accessibility at low cost to allow the country to grow.

Infrastructures require high installation costs, imposed by the need to provide common accessibility at low cost and non-discriminatory. The entity of the costs therefore requires that their management be public, state or at least regulated.

Network infrastructures and specific infrastructures exist according to the location. The former are characterized by being a network of systems and services interconnected by specific nodal points. There are transport networks, energy networks, networks composed of roads, railways, canals, gas pipelines, oil pipelines, etc. Telecommunication 
networks (telephone network, television broadcaster, radio broadcaster but also the computer network as a whole) are also of the same type, vital (aqueducts), drainage (sewage) and soil protection (waste disposal plants, so as the prevention networks of hydro-geological risk).

The specific infrastructure instead has value as such. Examples are hospitals, schools but also the set of basic infrastructures consisting of prisons, police and army stations, courts etc.

\section{Development Coming from Infrastructures}

Infrastructures are a crucial element for development, they must be designed, evaluated and constructed according to the needs of the historical evolutionary moment of the population, sometimes linked to the demographic explosion, or to the need for social mobilization due to different causes, such as famines, wars and climatic phenomena, which creates large urban agglomerations. With regard to infrastructure for the less advanced countries of Africa, the African Development Bank report (AfDB AEO : Report 2018) shows that this is a great potential, but with an impact on very small inclusive growth. The key message in fact contained in the Africa's Infrastructure section, is that Africa must necessarily industrialize to get out of poverty and create jobs for at least 12 million young people who come to join the workforce every year. The new AfDB estimates suggest that the infrastructure needs of the African continent require an investment of 130-170 million US dollars a year, with a funding gap between 68 and 108 million USD. A small fraction of the global savings surplus together with the use of lowcost resources would already be enough to cover the gap in Africa and finance productive and profitable infrastructures.

\subsection{Kind of infrastructures}

We briefly describe the characteristics of the infrastructures and how they are subdivided.

- Real estate: such as roads, highways, bridges, dams, lighting systems, communication networks, etc. Fixed assets are classified as: buildings and structures, machinery and equipment, and other fixed assets. Buildings and structures are further classified as: housing, buildings in addition to housing, other structures and land improvements.

- The machines and equipment are further classified as: means of transport; computer, IT and telecommunications equipment (ICT); and other machinery and equipment. Transport equipment consists of equipment for moving people and objects. ICT equipment consists of devices that use electronic controls and also electronic components that are part of these devices. Other fixed assets are further classified as: cultivated biological resources include animal and tree resources, crops, and plant resources, which produce repeated products. If the cultivated biological resources can produce repeated products, such as animals bred for slaughter, trees cultivated for timber and individual plots for vegetables, they are not considered as real estate but as stocks (work in progress).

Finally, there are intellectual property products that are the result of research, development, investigation or innovation that leads to the knowledge that developers can 
market or use to their advantage for production. These products include exploration and evaluation of minerals, computer software, databases and entertainment, literary and artistic originals. ${ }^{2}$

\subsection{Priority in infrastructures}

If the infrastructures present a priority scale determined by the need to develop the resident community in the industrialized countries, the more this priority appears to be important for the developing countries and especially for the African ones. To this end we can refer to the Report of the African Development Bank "Africa infrastructure" to present the situation of the least advanced countries of this continent. AfDB has created an index called Africa Infrastructure Development Index (AIDI) with three important objectives:

1) to monitor and evaluate the state and progress of infrastructure development on the continent;

2) to support the distribution of resources within the AfDB recovery framework;

3) to contribute to dialogue policies inside and outside the bank.

Since we have already stated the reality of the infrastructures, in this part it is important to define the priorities by grouping them by groups, such as:

Energy, Water and Health, Information and Communication Technology, Transport, road and other sectors (aeronautics, railways, and maritime transport).

All the solutions adopted for the infrastructures take into account exclusively the risks and the chances of success of the project rather than the development coefficient that it brings to the country.

Therefore, what should be highlighted in the development plans is the priority in satisfying the needs of the population, evaluating for each country a grid of elements of development and not just of returns and risks as currently carried out. The problem of priorities remains the key element to understand which kind of infrastructure must be privileged in order to create a start-up engine that supports the development of communities in the different territories. For this reason it is necessary to evaluate not only the elements such as energy, water, transport and ICT as a whole, but to understand how the creation of an infrastructure is necessary for the progressive growth of the population's standard of living conditions. The program must aim at a progressive development that takes into account the different interactions between development and economic growth: the creation of a railway must not be evaluated only in terms of financial investment, but must be correlated to the needs of development of the territory, to the number of population, to its need to move, to the volume, to the goods, to the saving of time, to the ability to produce work not only in terms of construction, but also in terms of maintenance and construction of punctual infrastructures such as hospitals, schools, universities, factories, stadiums, tourist parks, etc.

\subsection{Infrastructure financing}

Africa needs to finance an infrastructure plan adapted to the needs of its own countries, and not only for the development of the same, but also for the survival of the

${ }^{2}$ http://www.treccani.it/enciclopedia/infrastrutture \%28Enciclopedia-delle-scienze-sociali\%29/ 
advanced countries, whose amount of financial resources available is huge. As we know, Africa is still a continent with closures, economic difficulties and internationalization problems, still caught in the grip of debt and development linked almost exclusively to the production and sale of raw materials. Industries are managed by multinational companies from advanced countries. Political instability is another element of risk. Globalization penalizes, due to the inability to operate through the so-called value chains, the different processes of transformation, transport and distribution in the new model of technologically advanced commercial presence such as e-commerce. To remedy this there is need for an efficiency of infrastructures that make the installation of productive activities more convenient: transport is easier, water resources are more accessible, foodstuffs are more available, hospitals and health resorts are more accessible, as well as schools and universities, human capital is more widespread and institutions as social capital more responsive.

The cost of financing infrastructure if we look at AIDI in its five major components (Electricity, Water and Sanitation, ICT, Transport) tells us that in 2014 the proportion of the population with access to electricity in Africa was estimated to be $47 \%$ against $97 \%$ in Latin America and 89\% in Asia. While access to drinking water and sanitation was $47 \%$ in urban areas, compared to $34 \%$ in rural areas and in the whole of the continent, access to improved sanitation was $36 \%$ in 2015 against $83 \%$ of Latin America and $62 \%$ of Asia. Also with regard to access to drinking water in Africa it was $70 \%$ against $90 \%$ in Latin America. As for ICT, despite the widespread use of mobile phones and mobile applications, the spread of the internet now necessary for commercial, communication and technology applications has developed very slowly over the last ten years( AfDB $\mathrm{AEO}: 71)$.

\section{How Determine the Infrastructures Weight in Their Contribution to the Development}

The difficulty of assessing priorities in the creation of infrastructures and their consequent financing consists in the inability to get out of a tradition that bases its judgment on two strategic errors: the first deriving from the cultural concept of development: as a re-proposal of the uniform model of Western industrialization; the second is the need to obtain a financial profitability of the loans disbursed, in line with the capital market, without taking into account that many developing countries do not have easy access to the capital market in addition to suffering adverse trends in the rate of interest and the dollar exchange rate. Unfortunately, the phenomenon of infrastructures is evaluated only on the basis of financing and maintenance costs, which the lenders, on the basis of capitalist investment calculations, carry out by inducing governments to adapt to infrastructure development plans that do not consider the actual need for an infrastructure, but the amount of easier returns for Western suppliers. This can be easily understood from the fact that "for Africa the share of investment in transport infrastructure is the most consistent and reaches $39 \%$, followed immediately by that of the energy sector with $32 \%$, then the investment for the infrastructures for drinking water and sanitation with $17 \%$ while the ICT sector, which is constantly growing, is worth less than 3\%, as per table 3.4." (AfDB - AEO : 76 tab. 3.4) 
A study by UNIDO calculated that for each percentage point of GDP increase in Africa due to the manufacturing sector there is an increase in the per capita investment of around 66 dollars, which translates into an increase in individual consumption of 190 dollars. This increase in investments and consumption implies a demand for an increase in imports of capital goods and consumption from the entire developed world of the G20, the primary source of African imports. This context of increased production and consumption goods in the G20 and in Africa would set in motion several multiplier effects that generate further demand for intermediate goods, with an increase in incomes and certainly in employment. UNIDO estimates that by increasing the manufacturing quota in terms of Gross Domestic Product in Africa and in other developing countries, this could push investments in the G20 countries by about 485 billion dollars and in household consumption of around 1,400 billions of dollars.

\subsection{Structural characteristics of infrastructures}

The urban and interurban infrastructures of a country must be analyzed in terms of their structural functionality, meeting important criteria for assessing their implementation and their functionality with regard to use.

Each infrastructure with all its intrinsic and complementary features should be assessed in the project and funding plan, in the following profiles:

1) the priority of construction for conditions of livability that it improves on the territory, with reference to the needs of subsistence of the population, in respect of the SDGs especially the n. 9 in terms of industrial, technological and above all integral human development, ecological and environmental. ${ }^{3}$

2) the need for their creation for the functioning of existing structures, such as a) a road linking two cities; b) an energy transport network in a geographical area where there are factories, offices or other activities that require energy for their operation; c) water and sewerage networks or waste disposal networks where there are large urban aggregates with lower level infrastructures, such as hospitals, schools, universities and other human aggregation points; d) technological systems such as telephone network, internet, virtual communications, both for social use and for manufacturing and industrial use.

3) consistency with the needs of the area in which they are implemented;

4) maintenance difficulties assessed on: early degradation, installation difficulties, recovery difficulties at acceptable costs in periods of less than 3 months.

5) discomfort brought about by the interruption of the use of the infrastructure, both in terms of subsistence of the population and in economic and socio-relational terms;

6) planning of planned installation programs based on: a) structural survey and surveys of the state of usability; b) assessment of the actual state of the infrastructure under optimal operating conditions; c) design and optimization of restoration interventions with eco-socio-compatible solutions and innovative technologies.

7) assessment of the immediate and prospective social impact in respect of shared conditionality.

\footnotetext{
${ }^{3}$ One thing to note is that in the AfDB Report 2018, in box 3.5 "Employment, industrialization, and Sustainable Development Goals", all the goals, from n. 1 to n. 17 , are re-called less than the n. 9 which is precisely that concerning infrastructures.
} 


\subsection{How much is their weight on the path to development}

The weight of infrastructures along the path to development must be measured based on the needs first and foremost of the reference territory based on environmental sustainability, on the ability to contain or reduce air pollution; on the possibility of improving the working and living conditions of the people and social groups who use them; on the reliability, resistance and security of the services assessed on the rate of increase of the indicator of the standard of living that the infrastructure provides; on the creation of a historical archive of the data of the reference indicators of the contribution to the development of each infrastructure such as the functionality of schools, hospitals, universities, industries etc., with a weight priority in a hierarchical scale built on the needs of social development and inclusion with respect to the industrial economic one. Currently, however, the weight that is measured concerns only the gap between what is estimated and what is actually achieved. This is evidenced in several studies (AfDB report (2018): 80) by a Mc Kinsey study on infrastructures which found a need to invest, in the whole world, an average of 3,300 billion a year just to support current expectations of the estimated growth rate of which $60 \%$ should be attributed to developing economies. ${ }^{4}$

If we want to calculate the financing needs, we can refer to what is highlighted in terms of measuring the financing gap, in box 3.2 "Practical lesson on Stocks of infrastructures, needs and gaps". (AfDB (2018): 69

\subsection{How their contribution to development can be calculated}

All the in-depth analyzes carried out on the reality of infrastructures, especially with regard to the least advanced countries, take into consideration the need to create infrastructures, but not according to their contribution to development, which is not considered, but to their function of multiplying industrialization which must be one of the basic conditions for which infrastructure financing opportunities can be created. Also in the AfDB 2013 report there are some surveys presented in some schematizations: "Tables 5.1 and 5.2 presented on page 54 of the report use a system of traffic light indicators to represent scores on progress made at four levels. For level 1, the performance relative to the social progress of Africa is measured by comparing its way of progressing with that of the group of countries of the same level (low and middle income of countries around the world) and the good are highlighted results obtained in social inclusion and the progressive reduction of waste and pollution; for Level 2 of the Bank concerning the impact of the operations carried out, the performances are measured by comparing the expected result with that achieved for all the operations that have been completed, highlighting the good performance in the regional integration through the distribution of energy and in the private and agricultural sector, in the development of infrastructures related to transport, energy, water and sanitation, as well as ICT; performances are also good in the development of the skill and technology sector, especially for Vocational Training and health, while the Education sector still lags behind; with regard to Governance and responsibility, performance is good only in the

4 It is interesting to analyze the Mckinsey report: https://mckinsey.com/industries/capital-projects-andinfrastructure/our-insights/infrastructure-productivity 
competitive environment sector, with impacts on financial management and transparency in the public sector at low levels. For levels 3 and 4, the Bank's progress is measured with respect to its progress in achieving the 2013 objectives set by the Bank in its performance measurement model. The Level 2 scores therefore indicate that the Bank has made good progress in its support for African infrastructure, the private sector, and the development of skills and technology. It made moderate progress in his support for governance and regional responsibility and integration. A more detailed account is provided in Table 5.2 of pag. 55-56, (AfDB Report, (2013): 54-56) which presents the contribution that the Bank is making to the development of its operations in Africa. An index for the measurement of actual development, in which the weight of the infrastructures is also included on the side of the creation of value in support of the "standard of living" of the people and the human aggregates existing on the territory, can be calculated by taking as reference, instead of GDP5 growth, the idea of UPI that had already been proposed in the congress of the 5 ICSD. (European Journal of Sustainable Development (2017), 6, 4 ).

Taking up that proposal again, we could evaluate the following procedure:

Unexploited Potential Index and Infrastructure as

An index for the measurement of actual development

Unexploited Potential Index (UPI)

The Unexploited Potential Index (UPI) expresses the potential that has not yet been used in a given environment of a Country. Originates from:

- Estimate of the maximum exploitation that can be achieved with the existing resources

- Potential resources to exploit

From these resources, an estimate of the $\boldsymbol{U P I}$ is calculated.

The $\boldsymbol{U P I}$ is part of a wider index, the $\boldsymbol{T P I}$, Total Potential Index obtained from the $\boldsymbol{U P I}$ plus the $\boldsymbol{E P I}$ Expressed Potential Index obtained from:

- Resources present at the current state of exploitation.

So:

$\mathrm{TPI}=\mathrm{EPI}+\mathrm{UPI}$

We will use $\boldsymbol{T P I}$ as a reference to understand how much $\boldsymbol{S}_{\boldsymbol{I}}$ Standard of living can reach in the context considered.

NOTE: the value of the $\boldsymbol{U P I}$ may vary over time for many reasons, for example if a resource is discovered that was not known, or if new ways are found to exploit existing materials, etc.

\section{Infrastructure}

In order to improve Standard of living, $\mathbf{S}_{\boldsymbol{I}}$ certain activities must be carried out. These activities in turn must produce income $\mathbf{R}$.

The means to accomplish all of the above are identified in the $\mathbf{I}_{\boldsymbol{J}}$ infrastructures.

Infrastructures can be categorized as follows:

- Energy available

- Transportation

${ }^{5}$ which does not define development, but only a growth in numerical value, linked to a division between the value created in the territory, regardless of whether it is due to positive or negative causes, in relation to the population in terms of the cost of the factors, in terms of income paid or in terms of consumption. 
- Water and Sanitation (intended as a healthy environment)

- Information Communication Technology (ICT)

Every $\mathbf{I}_{\boldsymbol{J}}$ infrastructure falls into one of these families.

Each infrastructure will have $\mathbf{I}_{\boldsymbol{V}}$ activities whose value is given by:

- Intrinsic value $\mathbf{V}_{\boldsymbol{I}}$. the value that characterizes the structure, for example: costs, the material used, etc.

- Value created $\mathbf{V}_{\boldsymbol{C}}$ the value obtained from all the advantages that the infrastructure brings, for example: commuter transport to the workplace, disease prevention, etc.

It is evident that the created $\mathbf{V}_{C}$ value of an activity is the summation of the various $\boldsymbol{R} i$ incomes produced by its use:

$V_{C}=\sum_{i=1}^{N} R_{i}$

From this it follows that the $\boldsymbol{I}_{\boldsymbol{V} \boldsymbol{J}}$ value of each activity is given by:

$I_{V J}=V_{I}+V_{C}$

and consequently, for each $\boldsymbol{I}_{\boldsymbol{J}}$ infrastructure (category):

$I_{J i}=\sum_{k=1}^{M} I_{V J k} \quad i=1, \ldots, L$

The Standard of living $\boldsymbol{S}_{\boldsymbol{I}}$ is defined as the aggregate of the quantities with which goods and services pass from the production process to the Standard of living. This index can be calculated as the ratio between the absolute value of the product $\boldsymbol{V}_{\boldsymbol{A} \boldsymbol{P}}$ and the $\boldsymbol{T P I}$ total potential index:

$S_{l}=\frac{V_{A P}}{T P I} \cdot 100$

It is immediate to note that the maximum Standard of living that can be achieved is obtained when the absolute value $\boldsymbol{V}_{\boldsymbol{A} \boldsymbol{P}}$ produced reaches the $\boldsymbol{T P \boldsymbol { I }}$.

\section{Conclusion}

To conclude, we cannot but resume the discussion on the need for a paradigm leap in the evaluation of development. The path of reflection and research carried out focused on six important points, aimed at the shared definition of concepts concerning development, economic growth, infrastructures and their impact on development, to define a plausible way to measure their incidence in human development, of people and communities. The limits of work are given by the limited space of presentation and the difficulty of framing in a scientifically coherent way the variables touched in the research, which would need a deep and greater analysis. However, a useful debate is hoped to increase the cultural level necessary for the path towards development. In fact, as we have noted the problem of economic culture, or rather, of the sustainable use of resources and not of their simple exploitation for monetary and financial enrichment, it requires the will to identify a new way of interpreting the economy in a new economic vision, ${ }^{6}$ which I suggest to set, through the work of the School of Economics of integral human development, on the thought of B.J. Lonergan, which I summarize in this brief quote on the rhythms of development: "Significantly different combinations of DA 'and

\footnotetext{
${ }^{6}$ Also requested by Pope Francis with his "Open letter to economists from around the world - Economy of Francesco" http://w2.vatican.va/content/francesco/it/letters/2019/documents/papafrancesco 20190501 giovani-imprenditori.html
} 
$\mathrm{DA}^{17}$ as constant or increasing give the four cyclical phases of this ebb and flow: a capitalist phase that transforms the means of production; a materialistic phase that exploits new ideas to raise the standard of living; a cultural phase that allocates well-being and material power to provide means for the development of cultural activities; a static phase in which the process lies unproductive and non-economic activities develop independently of material conditions." (B.J. Lonergan (2013): 63).

I invite researchers and scholars to deepen the above calculation of my proposal, ${ }^{8}$ to verify its scientific configuration and its possible application, in addition to finding an additional "comparative disadvantage index" due to the absence of infrastructures, or a "contribution index to democratic openness", as social facilitation, induced by infrastructures and others to study and scientifically define how to insert an assessment of the actual contribution to development inherent in the implementation of infrastructures aimed at a truly sustainable, fair and lasting development.

\section{References}

African Development Bank. (2011). Private Sector Development as an Engine of Africa's Economic Development.

Abidjan, Cote d'Ivoire. Available at: https://www.afdb.org/fileadmin/uploads/afdb/Documents/Publications/African\%20Developm ent $\% 20$ Report $\% 202011$.pdf

(2013). “The Africa Infrastructure Development Index (AIDI).” AfDB Chief Economist Complex. Abidjan, Cote d'Ivoire. Available at: https://www.afdb.orgfileadmin/uploads/afdb/Documents/Publications/Economic Brief The Africa Infrastructure Development Index.pdf

Rifkin J. (2001) «L'era dell'accesso » Oscar Mondadori, Milano

Bhattacharya, Amar, Oppenheim J., and Stern N. (2015). "Driving Sustainable Development through Better Infrastructure: Key Elements of aTransformation Program." Global Economy and DevelopmentWorking Paper 92, Brookings Institution, Washington, DC.

Paolo VI, P.P. n. 87 (1984) in "Le Encicliche Sociali dalla Rereum Novarum alla Centesimus Annus" Ed. Paoline Milano

Ciminello R. "Manifesto della Scuola di Pensiero di Economia dello sviluppo integrale dell'Uomo, Kinshasa (RDC) 2013 -. http://agenda-etica.blogspot.com/2013/12/etica-e-prospettive-di-speranza-nello 5.html

Concilio Vaticano II (1984), Costituzione Pastorale Gaudium et Spes Ed. Paoline Milano

Economie du Developpement rural pag. 14-16 FORMDER- ISBN : 2-85352-380-2 ;

Cecilia Ugaz (22/9/2008) Directrice Adjointe Bureau du Rapport sur le Developpement Humain N.Y. BMRDH/BRA Atelier Technique Regional sur la Mesure du Developpement humain - Dakar,

Ciminello R. (2017) , European Journal of Sustainable Development , 6, 4, 370-386 ISSN: 2239-5938 -Doi: 10.14207/ejsd.2017.v6n4p370

Lonergan B.J. (2013): Studi di Economia, per una nuova economia politica, Ed. Città Nuova Roma,

Papa Francesco, (2019) "Lettera aperta agli economisti di tutto il mondo - Economy of Francesco" http://w2.vatican.va/content/francesco/it/letters/2019/documents/papafrancesco 20190501 giovani-imprenditori.html

Papa Francesco (2016) Enciclica “Laudato Si”, Libreria Editrice Vaticana - Roma

${ }^{7} \mathrm{DA}$ indicates the aggregate of all the basic rhythms of economic activity (A) and a series of events (D). DA' is the aggregate of primary rhythms, of routines that are factors of production at the lower level. DA" is the aggregate of secondary rhythms, these rhythms include everything that has an acceleration function with respect to the primary rhythms. cfr. B.J. Lonergan note 19, p. 49.

8 for whose correct mathematical formulation I must thank Prof. Felice Bruno of the University of Tuscia with whom I compared to give the maximum scientific clarity to the concepts expressed 